\title{
Clinical Evaluation of Bioactive Restorative Material versus Resin Modified Glass lonomer in Cervical Restorations: A Randomized Controlled Clinical Trial
}

\author{
Yehia Hafez Yehia*(D), Amir Hafez Ibrahim, Eman Abou-auf, Amira Farid Elzogbhi \\ Department of Conservative Dentistry, Faculty of Dentistry, Cairo University, Cairo, Egypt
}

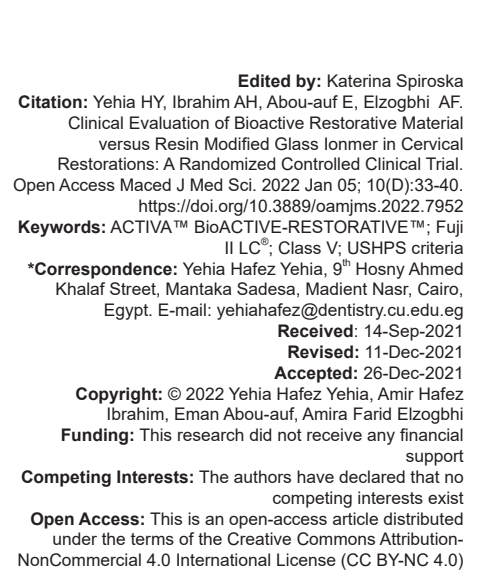

\section{Introduction}

Dental caries represent one of the most significant and prevalent problems in oral health. The rates of recurrent caries for restorative polymer materials are very high and it has been identified as one of the major reasons for the failure of resin composite restorations. Recurrent carious lesions are frequently located at the gingival margins of the proximal restorations, which are common areas for biofilm accumulation [1].

Fluoride-containing restorative materials gained great attention. Fluoride decreases caries activity by being a bacteriostatic and by decreasing the solubility of enamel and dentin through its integration into tooth tissue to form a more decay-resistant fluoroapatite [2]. Moreover, it aids to remineralize defected tooth structure after demineralization. To enhance the mechanical properties of Gls, their constituents have been modified. Comparatively, resinmodified GIs (RMGIs) with a longer working time, faster setting, higher early strength, and improved appearance and translucency [3]. Progressive development of material sciences has resulted in the introduction of bioactive restorative materials [4]. These materials can activate a tissue repair mechanism, elicit a response from teeth and surrounding environment [5].

Cervical lesions restorations are posing a challenge to the dental profession [6]. Cervical adhesive restorations failure is often attributed to inadequate moisture control, adhesion to different opposite substrates (enamel and dentin), differences in dentin composition, and great flexural stresses acting on the restoration that may lead to early loss or fracture [7]

The "smart materials" term is applied to material that can be altered in a controlled fashion by stimuli, such as $\mathrm{pH}$, stress, temperature, moisture and can return to the original state after the stimulus removal [8]. A novel bioactive restorative material has been developed known as ACTIVA Bioactive Restorative (Pulpdent Corp., Watertown, MA, USA). The manufacturer claimed that it imitates nature and participates in this dynamic ionic exchange as responding to change in oral environment [9]. It is water-based or has the capacity for significant water transport or storage. It can continuously 
release and recharge their ionic components with physical properties such as resin composite with release and recharge of calcium, phosphate, and fluoride similar to glass ionomers [10], [11].

Literature questioned ACTIVA whether it is resin-based composites with RMGI properties or a RMGI that has resin-based composite physical strengths [12]. Perdigão stated that a similar material has been approved by the FDA as a RMGIC [13]. ACTIVA has both light polymerization ability and chemical cure are involved so it was considered equivalent to resin-modified glass ionomers (RMGI), which their manufacturer claims to possess the general properties of a RMGI with modified resin matrix with enhanced resilience and physical properties [14].

Bhadra et al. evaluated the clinical performance of nanohybrid composite with Activa in Class II carious lesion [15]. Activa was used after etching only without bonding and there was no significant difference between them. van Dijken et al. clinically evaluated ACTIVA with etching only in comparison to nano-filled composite in posterior restorations, the results showed annual failure rates of $24.1 \%$ for the ACTIVA and $2.5 \%$ for Resin composite. The authors assumed that the main factor of failure is the very weak initial bond to the cavity walls, which could not counteract the polymerization stress, as well as thermal- and occlusal stresses, that caused a progressing deterioration of the interfacial adaptation [16]. Moreover, Garoushi et al. stated that the presence of high postoperative hypersensitivity results after ACTIVA application continues for days before replacement due to low burst of fluoride in comparison to glass-ionomer restoration and absence of long-term fluoride release and recharge [14].

With the development of newer materials in the market, clinician often gets confused regarding the choice of best materials to reach optimum results. Due to the limited evidence-based information in the literature regarding $\mathrm{RMGI}$ with bioactive restoration in class $\mathrm{V}$ cavities. It was found beneficial to evaluate the newly introduced material using a randomized controlled trial to test the null hypothesis that bioactive restoration will have the same clinical properties of RMGI in Class $\mathrm{V}$ cavities.

\section{Materials and Methods}

\section{Tested materials}

Material's specifications, chemical composition are represented in Table 1, as specified by the manufacturer.
Table 1: Tested materials

\begin{tabular}{|c|c|}
\hline Materials & Composition \\
\hline Glassionomer restorative & Distilled water: $20-30 \%$ \\
\hline \multirow[t]{5}{*}{ material (Fuji II LC@ capsules) } & Polyacrylic acid: $20-30 \%$ \\
\hline & HEMA: $30-35 \%$ \\
\hline & UDMA $<10$ \\
\hline & Camphorquinone $<1$ \\
\hline & fluoroaluminosilicate glass \\
\hline Dentin Conditioner & $10 \%$ Polyacrylic acid, $90 \%$ Distilled water (by weight) \\
\hline Glass ionomer coat & Light-cured protective clear coating formulated with \\
\hline $\begin{array}{l}\text { (EQUIA-Coat, GC) } \\
\text { ACTIVA }^{\text {TM }}\end{array}$ & $\begin{array}{l}\text { adhesive monomer and uniformly dispersed nanofillers. } \\
\text { Matrix: diurethane modified by the insertion of a }\end{array}$ \\
\hline \multirow[t]{2}{*}{ BioACTIVE-RESTORATIVE ${ }^{\text {M }}$} & $\begin{array}{l}\text { hydrogenated polybutadiene and other } \\
\text { methacrylate monomers, modified polyacrylic } \\
\text { acid, sodium fluoride }\end{array}$ \\
\hline & Filler: 56 wt. $\%$ ( $50 \%$ bioactive glass and ca. $7 \%$ silica) \\
\hline Etch-Rite ${ }^{\mathrm{TM}}$ & $\begin{array}{l}38 \% \text { Phosphoric acid, Water, Synthetic amorphous } \\
\text { silica, Polyethylene glycol }\end{array}$ \\
\hline Prime\&Bond universal & $\begin{array}{l}\text { Mono-, di-, and trimethacrylate resins; } 10-M D P, \\
\text { PENTA diketone; organic phosphine oxide; stabilizers; } \\
\text { cetylamine hydrofluoride; acetone; water }\end{array}$ \\
\hline
\end{tabular}

\section{Study design}

The present study is one-year follow-up examination of a prospective controlled randomized clinical parallel study design. The clinical performance of two restorative materials for the restoration of class $\mathrm{V}$ cavities in anteriors and premolars. The study was planned of independent cases and controls. Assuming a Type I error of 0.05 , a power of $80 \%$. Sample size so 18 teeth in each group to compensate for losses during follow-up, it was calculated based on the previous study by Perdigao et al. [17].

The study design followed the requirements outlined in the CONSORT 2010 statement and trial was approved from Evidence-Based Dentistry Committee of the Conservative Dentistry Department - Faculty of Dentistry, Cairo University. All procedures performed in this study, involving human participants were in accordance with the ethical standards of the Research Ethics Committee of Faculty of Dentistry, Cairo University (CREC), (Ref. 19/1/17). It was registered in (www.clinicaltrials.gov) database, with unique identification number NCT03771196. The trial design is a randomized, two parallel arms, double blind, clinical trial held in the outpatient clinic of the Conservative Dentistry Department - Faculty of Dentistry, Cairo University.

\section{Patient selection}

Thirty-six patients were recruited for this clinical trial from the outpatient clinic of the Conservative Dentistry Department - Faculty of Dentistry, Cairo University. The inclusion criteria for patients were males or females with age range 18-40 years having Cervical Class $\mathrm{V}$ carious lesions in anterior or premolars teeth. The patients with Systemic disease or severe medical complications or Allergic history concerning methacrylates were excluded from this study. Small to moderate class $\mathrm{V}$ carious lesion in vital upper or lower teeth, with no signs of irreversible pulpitis or symptoms of hypersensitivity, and caries cervical margins above 


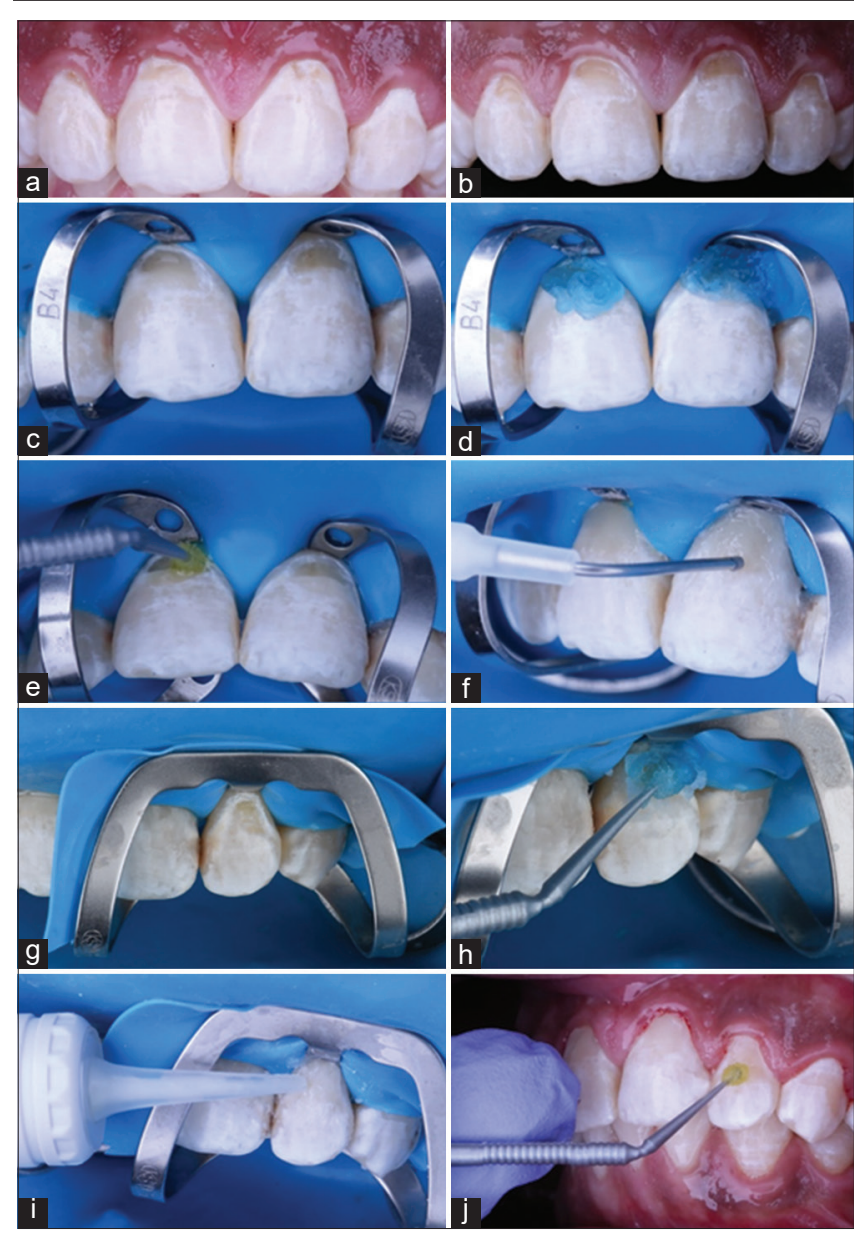

Figure 1: (a) Cervical carious lesions (b) cavity preparations (c) cavity isolation; the two centrals restored by ACTIVA and two lateral restored by FUJI II LC (d) etching of cavities (e) application of adhesive (f) application of ACTIVA inside the cavity (g) Cavity preparation and isolation for FUJI II LC (h) application of cavity conditioner (i) application f FUJI II LC capsule inside the cavity (j) application of EQUIA-coat over the restoration

CEJ were selected in this study. All eligible patients signed an informed consent containing all the ethical aspects of the trial.

Each tooth has a random number from (1-36), then simple randomization was done using Random Sequence Generator (https://www.random.org/). The generated random number from 1 to 18 represented the control group and from 18-36 represented the intervention group. The operator chose between numbers in an opaque sealed envelope, which was arranged by the assistant, who was not involved in any of the phases of the clinical trial. The side to which the restorative material was assigned was recorded. The operator was not blinded to the material assignment because of the difference in the application protocol of the restorative materials, which prohibited blinding of the operator; however, the assessors and participants were blinded to the material assignment (Figure 1).

Patients were given local anesthesia (Mepecaine - L Cartridges) as required, and the teeth were isolated. A No. \#330 bur (MANI, INC, Japan) in a high-speed handpiece with air/water coolant was used to prepare class $\mathrm{V}$ cavity. The prepared cavity was isolated with rubber dam (Sanctuary Health Sdn Bhd) and Sub-gingival clamps (KSK, DENTECH Corporation, Japan) (Figure 1a, b and c).

\section{Clinical restorative procedures}

\section{ACTIVA bioactive restorative}

The material was applied according to manufacturer instructions as follows: The prepared cavities were conditioned for 10 seconds using Etch-Rite 38\% phosphoric acid etching gel [16]. The surfaces were rinsed and dried with compressed air, removing all excess moisture without desiccating the dentin structure. Then, application of Prime\&Bond universal Dentsply Sirona to all cavities with bond brush. then photocured for $10 \mathrm{~s}$ using an LED lightcuring unit with curing intensity $1000-2400 \mathrm{~mW} / \mathrm{cm}^{2}$ (I Led Guilin Woodpecker Medical Instrument Co., Ltd. China). ACTIVA Bioactive restorative was applied in one bulk increment, adapted by gold plated composite applicator (Aesculap, Inc., USA) inside the cavity then light polymerized for $20 \mathrm{~s}$ using light-emitting diode light-curing unit (Figure 1d, e and f).

\section{GC Fuji II LC® capsule}

The prepared cavities were isolated with a rubber dam and conditioned for $20 \mathrm{~s}$ using Dentin conditioner $10 \%$ polyacrylic acid, then rinsing for 20 s. Restoration was adapted by gold plated applicator then light cured for $20 \mathrm{~s}$ for every $2 \mathrm{~mm}$ increment. EQUIA-Coat ${ }^{\mathrm{TM}}$ was applied over the restoration immediately after finishing then photo-cured for $20 \mathrm{~s}$ [5] (Figure 1g, h, i and j).

\section{Finishing}

In order to remove excess filling and contouring, superfine yellow ringed finishing diamond stones (MANI, INC, Japan) were used under copious water coolant then Diamond discs were used for polishing (OptiDisc $^{\mathrm{TM}}$, Kerr Dental, USA).

\section{Clinical examination}

Table 2 showed the modified USPHS criteria for dental restoration, which were evaluated by two blinded assessors at baseline (1 week), after six months and after twelve months (Figure 2). The assessors filled evaluation chart for each restoration, when assessors had different scores, they discussed to reach for consensus. All evaluations were carried out under a dental operating light, using flat-surfaced mouth mirrors and sharp dental explorers in a proper isolated field. Two calibrated investigators evaluated the restorations, an initial agreement of at least $85 \%$ between evaluators was considered significant. If disagreement occurred 

expert was asked for evaluation (Table 3).

Table 2: Clinical evaluation using Modified USPHS criteria for dental restorations

\begin{tabular}{|c|c|c|c|c|}
\hline Criterion & Score & Characteristics & M. unit & Methods of diagnosis \\
\hline \multirow[t]{3}{*}{$\begin{array}{l}\text { Marginal } \\
\text { discoloration }\end{array}$} & A & $\begin{array}{l}\text { No discoloration between tooth } \\
\text { structure and restorative material }\end{array}$ & Ordinal & $\begin{array}{l}\text { The examination was } \\
\text { carried out by using }\end{array}$ \\
\hline & B & $\begin{array}{l}\text { Non penetrating marginal } \\
\text { discoloration which can polished } \\
\text { away }\end{array}$ & & $\begin{array}{l}\text { dental mirror and } \\
\text { explorer in a properly } \\
\text { isolated field }\end{array}$ \\
\hline & c & $\begin{array}{l}\text { Discoloration has penetrated } \\
\text { margin in pulpal direction }\end{array}$ & & \\
\hline \multirow[t]{3}{*}{$\begin{array}{l}\text { Marginal } \\
\text { adaptation }\end{array}$} & A & $\begin{array}{l}\text { Closely adapted, no detectable } \\
\text { margin }\end{array}$ & Ordinal & \\
\hline & B & $\begin{array}{l}\text { Detectable marginal discrepancy, } \\
\text { clinically acceptable }\end{array}$ & & \\
\hline & c & $\begin{array}{l}\text { Marginal crevice, clinically } \\
\text { unacceptable }\end{array}$ & & \\
\hline Surface & A & No surface defect & Ordinal & \\
\hline \multirow[t]{2}{*}{ Roughness } & B & Minimal surface defect & & \\
\hline & C & Severe surface defect & & \\
\hline \multirow[t]{3}{*}{ Color match } & A & $\begin{array}{l}\text { Restoration color matches color } \\
\text { of tooth }\end{array}$ & Ordinal & \\
\hline & B & Acceptable mismatch & & \\
\hline & C & Un-acceptable mismatch & & \\
\hline \multirow[t]{3}{*}{ Surface luster } & A & $\begin{array}{l}\text { Restoration surface is shiny look } \\
\text { like enamel }\end{array}$ & Ordinal & \\
\hline & B & $\begin{array}{l}\text { surface is dull and somehow } \\
\text { opaque }\end{array}$ & & \\
\hline & C & $\begin{array}{l}\text { Surface is dull and ethically } \\
\text { unpleasant }\end{array}$ & & \\
\hline Recurrent & A & No recurrent caries detected & Ordinal & \\
\hline Caries & C & Recurrent caries detected & & \\
\hline Retention & A & No loss of restoration & Ordinal & \\
\hline Analysis & C & Loss of restoration & & \\
\hline
\end{tabular}

\section{Data analysis}

MannWhitney test was used to compare between tested materials. Freidman test was used to test the effect of time within tested materials. Kruskal Wallis test was used to compare the interaction between variables for all tested parameters. The results were statistically significant when $p \leq 0.05$. All statistical analyses were performed using SPSS for Windows, version 25 (SPSS Inc., Chicago, IL, USA).

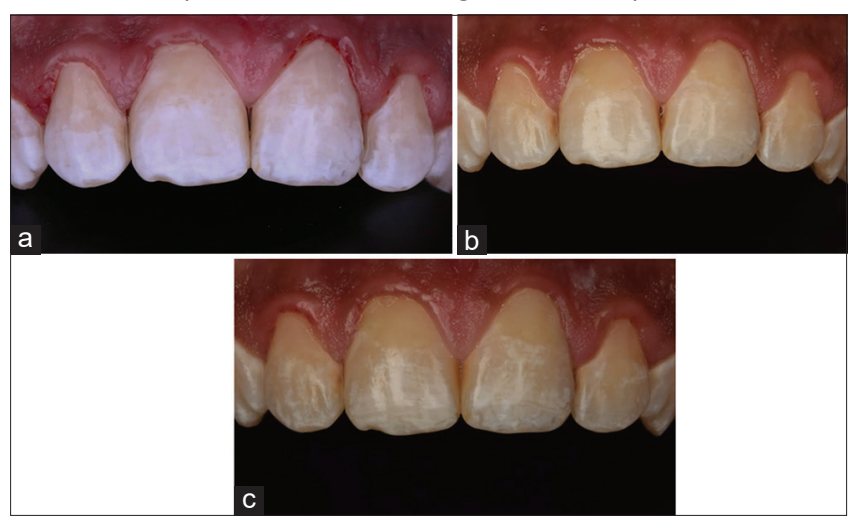

Figure 2: (a) Postoperative (b) after 6 months (c) after 12 months between the examiners, a third equally calibrated

showed the flow of participants through this study up to 12 months in accordance with the CONSORT 2010 statement [18]. Restorations were randomly placed in 30 anterior and six premolars in 12 females and eight males with 18 restorations each group. Performance of materials was tested for marginal discoloration, marginal adaptation, surface roughness, surface luster and color match, retention, and post-operative hypersensitivity according to modified USPHS criteria for dental restoration. The scores are either Alpha, Bravo, or Charlie, the alpha score for excellent restoration, Bravo for accepted restoration with minor repair while Charlie for unaccepted restoration needs to be replaced [19].

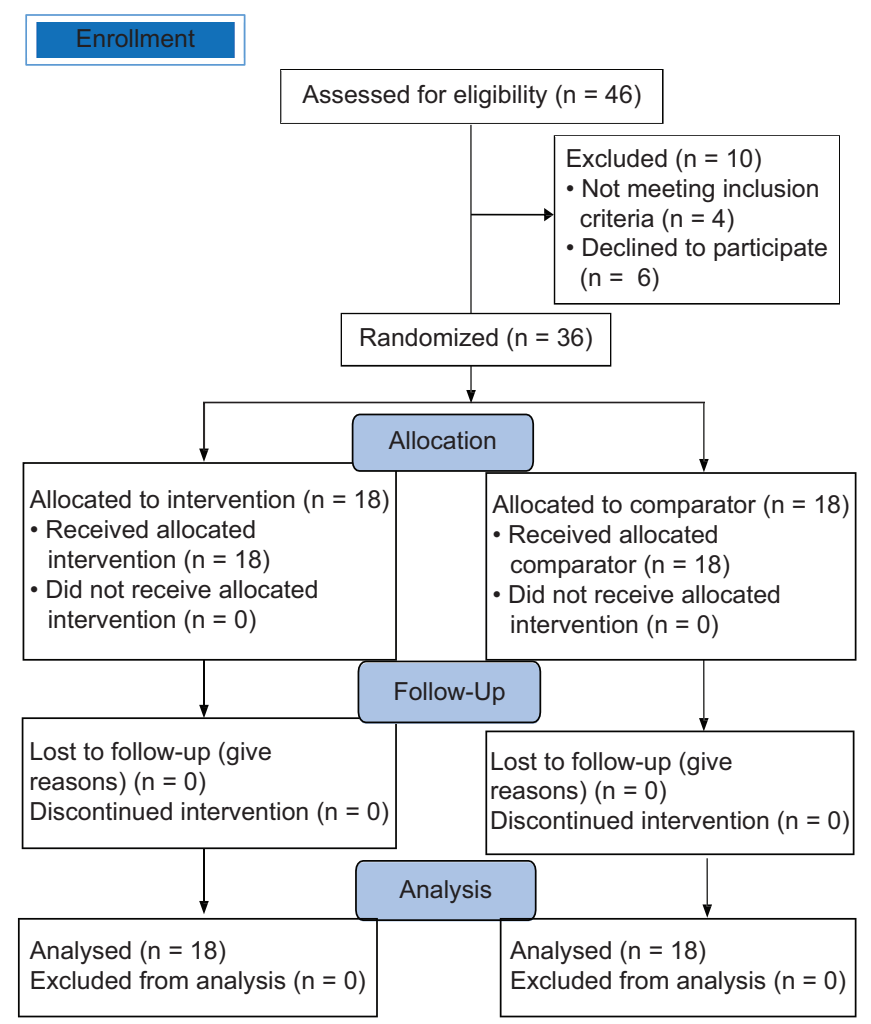

Figure 3: Flow of participants through the stages of this study

There was no significant difference between interaction of both restorations and time in marginal discoloration ( $p=0.051)$, recurrent caries $(p=1.00)$ and retention analysis $(p=1.00)$, but there was a significant change in marginal adaptation ( $p=0.001)$, surface roughness $(p=0.017)$, color change $(p=0.004)$ and surface luster $(p=0.017)$ with $100 \%$ survival rate in this study (Figure 4) and (Table 3).

\section{Discussion}

\section{Results}

All patients returned for 6 months and 12 months' follow-up visits; thus, the recall rate was $100 \%$. Figure 3
The available data concerning the use of ACTIVA $^{\text {TM }}$ BioACTIVE-RESTORATIVE TM (ACTIVA) as a tooth restoration in permanent teeth are limited and inconclusive in the literature [15]. The evidence from 


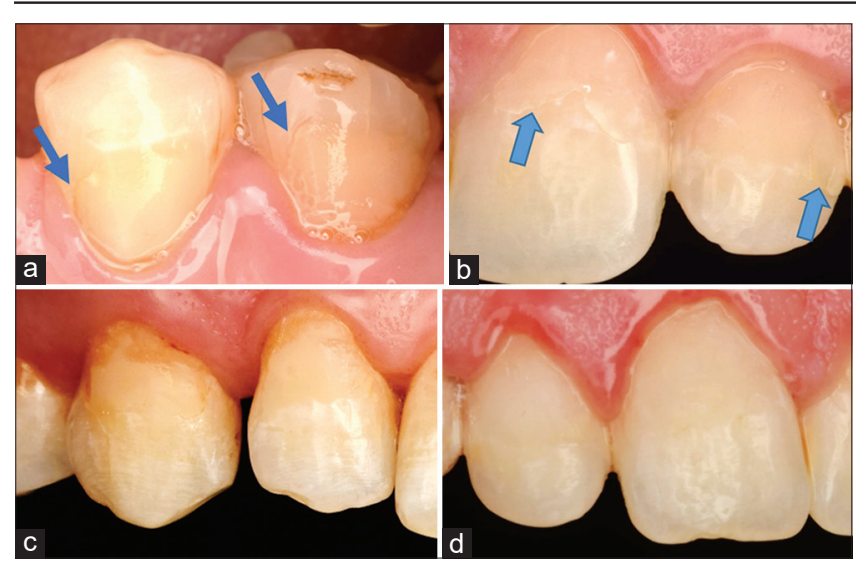

Figure 4: Representative photographs for assessed outcomes (a) marginal discoloration with Bravo score after 12 months (b) marginal adaptation with bravo score after 12 months (c) Loss of color match in upper lateral and canine after 12 months (d) Loss of surface luster in central and upper lateral incisors after 12 months with bravo score

in vitro studies and limited clinical trials with ACTIVA restorations placed after conventional cavity preparation appear to be insufficient for clinical guidance. The main bulk of available evidence represented as in vitro experiments which suggested that the remineralization and mechanical properties of bioactive restorations in permanent teeth are comparable to that of resin composite restorations. On other hand limited in vivo studies are controversial regarding the clinical evaluation of this new restoration [20].

The ionic resin component contains phosphate acid groups with antimicrobial properties that improve the interaction between the resin and the reactive glass fillers and enhance the interaction with tooth structure [15]. ACTIVA-Restorative contains the glass particles and polyacid components of glass ionomer, which undergo the acid-base setting reaction, they are also formulated with a bioactive ionic resin matrix, having both light polymerization ability and chemical cure [12].

According to the results obtained from the current study, after one year all restorations were evaluated with no drop-outs, the survival of restorations was $100 \%$. In the current study Bioactive restorative material (ACTIVA ${ }^{\mathrm{TM}}$ BioACTIVE-RESTORATIVE ${ }^{\mathrm{TM}}$ ) has shown clinical performance similar to resinreinforced restorative glass ionomer (RMGI) after one year of clinical service; therefore, the null hypothesis was accepted.

Regarding this study, marginal discoloration results showed there are two restorations scored Bravo in the control group while three restorations scored bravo in the intervention group after 12 months with no significant difference between the restoration groups $(p=0.791)$, but there was a significant difference within ACTIVA group over the time $(p=0.05)$. This result is in acceptance with Park et al. (2008) who attributed the difficulty of bonding to class $V$ cavity to high flexural
Table 3: Clinical data for restorations evaluation according to USHPS criteria (number of restorations (n) and percentages (\%)) are depicted for FUJI II LC and ACTIVA BIO-ACTIVE

\begin{tabular}{|c|c|c|c|c|c|}
\hline & \multicolumn{2}{|c|}{ Fuji II LC® } & \multicolumn{2}{|c|}{ ACTIVA $^{\text {TM }}$ BioACTIVE-RESTORATIVE ${ }^{\text {TM }}$} & $p$-value \\
\hline & $\mathrm{n}$ & $\%$ & $\mathrm{n}$ & $\%$ & \\
\hline Marginal disc & & & & & \\
\hline Baseline & & & & & \\
\hline Alpha & 18 & 100.00 & 18 & 100.00 & 0.051 \\
\hline Bravo & 0 & 0.00 & 0 & 0.00 & \\
\hline Charlie & 0 & 0.00 & 0 & 0.00 & \\
\hline 6 Months & & & & & \\
\hline Alpha & 18 & 100.00 & 18 & 100.00 & \\
\hline Bravo & 0 & 0.00 & 0 & 0.00 & \\
\hline Charlie & 0 & 0.00 & 0 & 0.00 & \\
\hline 12 Months & & & & & \\
\hline Alpha & 16 & 88.90 & 15 & 83.30 & \\
\hline Bravo & 2 & 11.10 & 3 & 16.70 & \\
\hline Charlie & 0 & 0 & 0 & 0 & \\
\hline Marginal ada & & & & & \\
\hline Baseline & & & & & \\
\hline Alpha & 18 & 100.00 & 18 & 100.00 & $0.001^{*}$ \\
\hline Bravo & 0 & 0.00 & 0 & 0.00 & \\
\hline Charlie & 0 & 0.00 & 0 & 0.00 & \\
\hline 6 Months & & & & & \\
\hline Alpha & 18 & 100.00 & 18 & 100.00 & \\
\hline Bravo & 0 & 0.00 & 0 & 0.00 & \\
\hline Charlie & 0 & 0.00 & 0 & 0.00 & \\
\hline 12 Months & & & & & \\
\hline Alpha & 14 & 77.78 & 13 & 72.22 & \\
\hline Bravo & 4 & 22.22 & 5 & 27.78 & \\
\hline Charlie & 0 & 0.00 & 0 & 0.00 & \\
\hline Surface roug & & & & & \\
\hline Baseline & & & & & \\
\hline Alpha & 18 & 100.00 & 18 & 100.00 & $0.017^{*}$ \\
\hline Bravo & 0 & 0.00 & 0 & 0.00 & \\
\hline Charlie & 0 & 0.00 & 0 & 0.00 & \\
\hline 6 Months & & & & & \\
\hline Alpha & 15 & 83.30 & 18 & 100.00 & \\
\hline Bravo & 3 & 16.70 & 0 & 0.00 & \\
\hline Charlie & 0 & 0.00 & 0 & 0.00 & \\
\hline 12 Months & & & & & \\
\hline Alpha & 13 & 72.20 & 15 & 83.30 & \\
\hline Bravo & 5 & 27.8 & 3 & 16.70 & \\
\hline Charlie & 0 & 0.00 & 0 & 0.00 & \\
\hline Color match & & & & & \\
\hline Baseline & & & & & \\
\hline Alpha & 15 & 83.30 & 18 & 100.00 & $0.004^{*}$ \\
\hline Bravo & 3 & 16.70 & 0 & 0.00 & \\
\hline Charlie & 0 & 0.00 & 0 & 0.00 & \\
\hline 6 Months & & & & & \\
\hline Alpha & 13 & 72.2 & 18 & 100.00 & \\
\hline Bravo & 5 & 27.8 & 0 & 0.00 & \\
\hline Charlie & 0 & 0.00 & 0 & 0.00 & \\
\hline 12 Months & & & & & \\
\hline Alpha & 10 & 55.6 & 14 & 77.8 & \\
\hline Bravo & 8 & 44.4 & 4 & 22.2 & \\
\hline Charlie & 0 & 0.00 & 0 & 0.00 & \\
\hline Surface luste & & & & & \\
\hline Baseline & & & & & \\
\hline Alpha & 18 & 100.00 & 18 & 100.00 & $0.017^{*}$ \\
\hline Bravo & 0 & 0.00 & 0 & 0.00 & \\
\hline Charlie & 0 & 0.00 & 0 & 0.00 & \\
\hline 6 Months & & & & & \\
\hline Alpha & 15 & 83.3 & 18 & 100.00 & \\
\hline Bravo & 3 & 16.7 & 0 & 0.00 & \\
\hline Charlie & 0 & 0.00 & 0 & 0.00 & \\
\hline 12 Months & & & & & \\
\hline Alpha & 13 & 72.2 & 15 & 83.30 & \\
\hline Bravo & 5 & 27.8 & 3 & 16.7 & \\
\hline Charlie & 0 & 0.00 & 0 & 0.00 & \\
\hline Recurrent ca & & & & & \\
\hline Baseline & & & & & \\
\hline Alpha & 18 & 100.00 & 18 & 100.00 & 1.00 \\
\hline Bravo & 0 & 0.00 & 0 & 0.00 & \\
\hline 6 Months & & & & & \\
\hline Alpha & 18 & 100.00 & 18 & 100.00 & \\
\hline Bravo & 0 & 0.00 & 0 & 0.00 & \\
\hline 12 Months & & & & & \\
\hline Alpha & 18 & 100.00 & 18 & 100.00 & \\
\hline Bravo & 0 & 0.00 & 0 & 0.00 & \\
\hline Retention an & & & & & \\
\hline Baseline & & & & & \\
\hline Alpha & 18 & 100.00 & 18 & 100.00 & 1.00 \\
\hline Bravo & 0 & 0.00 & 0 & 0.00 & \\
\hline 6 Months & & & & & \\
\hline Alpha & 18 & 100.00 & 18 & 100.00 & \\
\hline Bravo & 0 & 0.00 & 0 & 0.00 & \\
\hline 12 Months & & & & & \\
\hline Alpha & 18 & 100.00 & 18 & 100.00 & \\
\hline Bravo & 0 & 0.00 & 0 & 0.00 & \\
\hline
\end{tabular}


stresses on restoration that cause debonding [6]. Moreover, general difficulty in dentin bonding due to its heterogeneous structure, inherited wetness, collagentic activity of MMPS, and cysteine cathepsins. Regarding ACTIVA hydrophilicity of ionic resin matrix may be a double-sided weapon. It allows good bonding to hydrophilic dentin but this matrix can allow the fluids intake from oral cavity or fluid from induced from pulpal pressure results in plasticization of resin polymers, even though adding separate step of adhesive with 10-MDP cannot stop hydrolysis of methacrylate monomers in ACTIVA structure by salivary esterases. The esterases enzymes can break covalent bonds between the polymers by the addition of water to the ester bonds [21].

Large volumetric contraction, due to thermal stresses induced by thermocycling loading, which proved in a laboratory simulating oral conditions for ACTIVA may weaken bonding to tooth structure [22]. Another possible explanation is that the mixing procedure during preparation can result in the formation of bubbles before application, which may contribute to leakage. Moreover, the lower filler content of RMGI indicates a higher resin content, which increases the polymerization shrinkage and consequently the microleakage [5]. They also stated that the higher polymerization shrinkage in RMGI could be one of the factors causing a higher degree of microleakage in RMGI [4].

Significant difference results, regarding marginal adaptation, in each type of restoration can be attributed to high water sorption of RMGI, and hydrophilicity of ACTIVA which may cause plasticization of resin polymers over time. However, There was no significant difference between both materials regardless of the time.

On the other hand, regarding surface roughness, there was a significant change in each restoration over time and a significant difference in between both materials at different follow-up periods $(p=0.017)$. ACTIVA can retain the smoothness of its surface for six months for a longer period than Fujii $\mathrm{LC}$ restorations. ACTIVA has a similar wear rate as a conventional resin composite. This can be explained partially by the resilient resin matrix with energyabsorbing elastomeric components. Furthermore, the type, chemistry, morphology, and size of the filler have been found to influence the material hardness performance [10]. These results are in acceptance with Garoushi et al. who declared that the restorative composite material with small-sized filler particles reveals the improved hardness, SEM pictures showed that Fuji II LC had relatively fine fillers and this might explain the higher Vickers hardness values [18].

ACTIVA color's match was better at baseline and 6 months thanks to different shades provided by the manufacturer and low surface roughness recorded in both groups. There was a significant change in color in each group over the time for Fuji II LC $(p=0.022)$ and ACTIVA ( $p=0.018$ ) this can be attributed to water sorption and mineral exchange moreover the
ACTIVA's color match also significantly changed but still numerically less than Fuji group.

The same regarding surface luster all restoration recorded alpha at baseline with no significant difference between both materials, while there is a significant change in surface luster in each restorative group over time and significant difference between different material with different follow up periods. The decrease in gloss was attributed to increased roughness and change in surface topography resulting from the abrasion of the resin matrix and loss of surface filler particles. The amount of filler is not as important as its pattern of dispersion and the inter-particle spacing of filler particles, they also play an important role in surface protection [23].

There were no recurrent caries detected in any of the two groups. This result is expected due to the anticariogenicity feature of both restorations. In Fujii II LC the hydrophilic poly-hydroxyethyl methacrylate probably absorbs sufficient water to enable diffusion of fluoride ions that may otherwise be firmly encapsulated within the polyacrylate matrix with high calcium and phosphorous release in comparison to glass ionomer [24]. Also, these results are in acceptance to Ruengrungsom et al. (2020).

However, the bioactivity feature of ACTIVA is questionable as it is not only the ability to release calcium or fluoride, but it is the ability formation of apatite in the body like fluids, otherwise many restorative materials can be called bioactive one. Longer clinical studies with a larger sample size are needed to explore the anticariogenic effect over a long time [25].

The null hypothesis is accepted in this study. There was no significant difference between the overall clinical performance of both restorations over 12 months. Both restorations' performance is accepted with no failure during this study. With the evolution of caries management shifting to "minimally invasive" techniques, restorative materials are endowed with increasing expectations for therapeutic effects. Previously, glass-ionomer was considered an interim restoration and limited to caries control protocols, and considered unreliable for many clinical situations. However, with recent innovations and continued upgrading and developments in dental materials the hope of developing a new generation of antimicrobial, therapeutic, and bioactive resins increases. Hopefully, this innovative bioactive restorative material can go beyond the in vitro studies, prove successful in vivo studies and be available soon in the market.

\section{Conclusion and Recommendation}

Under the limitations of the current study, the following conclusions could be derived: Both ACTIVA ${ }^{\text {TM }}$ 
BioACTIVE-RESTORATIVE ${ }^{\mathrm{TM}}$ and Fuji II LC® are acceptable as long term provisional restoration. ACTIVA $^{\mathrm{TM}}$ BioACTIVE-RESTORATIVE ${ }^{\mathrm{TM}}$ proved to retain its esthetic characteristics over the conventional one. ACTIVA ${ }^{\text {TM }}$ BioACTIVE-RESTORATIVE ${ }^{\text {TM }}$ restorations with an adhesive system can be used as long-term restoration in small defined cavities, not in stress-bearing areas.

Clinical trials with longer follow-up periods and larger sample sizes are needed to confirm the current results. Clinical trials testing the performance of bioactive restorations in other clinical indications are encouraged, to recommend utilizing the new material in various clinical applications. Due to the limited evidence-based information, clinical trials comparing the clinical performance of bioactive restorations and resin composite are recommended.

\section{Ethics approval}

All procedures performed in this study were in accordance with the ethical standards of the institutional research committee and with the 1964 Helsinki declaration and its later amendments.

\section{References}

1. Nedeljkovic I, Teughels W, De Munck J, Van Meerbeek B, Van Landuyt $\mathrm{KL}$. Is secondary caries with composites a materialbased problem? Dent Mater. 2015;31(11):e247-77. https://doi. org/10.1016/j.dental.2015.09.001

PMid:26410151

2. Ruengrungsom $C$, Burrow MF, Parashos $P$, Palamara JEA Evaluation of $\mathrm{F}, \mathrm{Ca}$, and $\mathrm{P}$ release and microhardness of eleven ion-leaching restorative materials and the recharge efficacy using a new Ca/P containing fluoride varnish. J Dent. 2020;102:103474. https://doi.org/10.1016/j.jdent.2020.103474 PMid:32941973

3. Kucukyilmaz E, Savas S, Kavrik F, Yasa B, Botsali M. Fluoride release/recharging ability and bond strength of glass ionomer cements to sound and caries-affected dentin. Niger J Clin Pract. 2017;20(2):226-34. https://doi.org/10.4103/1119-3077.178917 PMid:28091442

4. Gerdolle DA, Mortier E, Droz D. Microleakage and polymerization shrinkage of various polymer restorative materials. J Dent Child (Chic). 2008;75(2):125-33.

PMid: 18647507

5. Omidi BR, Naeini FF, Dehghan H, Tamiz P, Savadroodbari MM, Jabbarian R. Microleakage of an enhanced resin-modified glass ionomer restorative material in primary molars. J Dent (Tehran). 2018;15(4):205-13

PMid:30405729

6. Park JK, Hur B, Kim SK. Stress distribution of class V composite resin restorations: A three-dimensional finite element study. J Korean Acad Conserv Dent. 2008;33(1):28-38.

7. Alkhudhairy FI, Ahmad ZH. Comparison of shear bond strength and microleakage of various bulk-fill bioactive dentin substitutes: An in vitro Study. J Contemp Dent Pract. 2016;17(12):997-1002.

\section{PMid:27965486}

8. Tamilsevi R, Anuradha B, Arunakumari V, Porkodi I, Sathyapriya B. Current trends in smart materials-a review. Indian J Public Health Res Dev. 2019;10(12):2536-9.

9. Owens BM, Phebus JG, Johnson WW. Evaluation of the marginal integrity of a bioactive restorative material. Gen Dent. 2018;66(3):32-6.

PMid:29714697

10. Bansal R, Burgess J, Lawson NC. Wear of an enhanced resin-modified glass-ionomer restorative material. Am J Dent. 2016;29(3):171-4.

PMid:27505995

11. Croll TP, Berg JH, Donly KJ. Dental repair material: A resinmodified glass-ionomer bioactive ionic resin-based composite. Compend Contin Educ Dent. 2015;36(1):60-5 PMid:25822408

12. Garcia-Godoy F, Morrow B, Pameijer C. Flexural strength and fatigue of new activa RMGICs. J Dent Res. 2014;93:254.

13. Perdigão J. Current perspectives on dental adhesion: (1) Dentin adhesion-not there yet. Jpn Dent Sci Rev. 2020;56(1):190-207. https://doi.org/10.1016/j.jdsr.2020.08.004

14. Garoushi S, Vallittu PK, Lassila L. Characterization of fluoride releasing restorative dental materials. Dent Mater J. 2018;37(2):293-300. https://doi.org/10.4012/dmj.2017-161 PMid:29279547

15. Bhadra D, Shah NC, Rao AS, Dedania MS, Bajpai N. A 1-year comparative evaluation of clinical performance of nanohybrid composite with activa bioactive composite in Class II carious lesion: A randomized control study. J Conserv Dent. 2019;22(1):92-6. https://doi.org/10.4103/JCD.JCD 511_18 PMid:30820090

16. van Dijken JW, Pallesen U, Benetti A. A randomized controlled evaluation of posterior resin restorations of an altered resin modified glass-ionomer cement with claimed bioactivity. Dent Mater. 2019;35(2):335-43. https://doi.org/10.1016/j. dental.2018.11.027

PMid:30527586

17. Perdigao J, Dutra-Correa M, Saraceni SH, Ciaramicoli MT, Kiyan VH. Randomized clinical trial of two resin-modified glass ionomer materials: 1-year results. Oper Dent. 2012;37(6):591-601. https://doi.org/10.2341/11-415-C PMid:22770485

18. Moher D, Hopewell S, Schulz KF, Montori V, Gøtzsche PC, Devereaux PJ, et al. CONSORT 2010 Explanation and Elaboration: Updated guidelines for reporting parallel group randomised trials. BMJ. 2010;340:c869. https://doi.org/10.1136/ bmj.c869

PMid:20332511

19. Bayne SC, Schmalz G. Reprinting the classic article on USPHS evaluation methods for measuring the clinical research performance of restorative materials. Clin Oral Investig. 2005;9(4):209-14. https://doi.org/10.1007/ s00784-005-0017-0

PMid:16421996

20. Alrahlah A. Diametral tensile strength, flexural strength and surface microhardness of bioactive bulk fill restorative. J Contemp Dent Pract. 2018;19(1):13-9. https://doi.org/10.5005/ jp-journals-10024-2205 PMid:29358529

21. Liu Y, Tjaderhane L, Breschi L, Mazzoni A, Li N, Mao J, et al. Limitations in bonding to dentin and experimental strategies to prevent bond degradation. J Dent Res. 2011;90(8):953-68. https://doi.org/10.1177/0022034510391799

PMid:21220360 
22. Benetti AR, Michou S, Larsen L, Peutzfeldt A, Pallesen U, van Dijken JWV. Adhesion and marginal adaptation of a claimed bioactive, restorative material. Biomater Investig Dent. 2019;6(1):90-8. https://doi.org/10.1080/26415275.201 9.1696202

\section{PMid:31998876}

23. Lassila L, Sailynoja E, Prinssi R, Vallittu PK, Garoushi S. The effect of polishing protocol on surface gloss of different restorative resin composites. Biomater Investig Dent. 2020;7(1):1-8. https:// doi.org/10.1080/26415275.2019.1708201

PMid:32010900
24. Porenczuk A, Jankiewicz B, Naurecka M, Bartosewicz B, Sierakowski B, Gozdowski D, et al. A comparison of the remineralizing potential of dental restorative materials by analyzing their fluoride release profiles. Adv Clin Exp Med. 2019;28(6):815-23. https://doi.org/10.17219/acem/94140

PMid:30740943

25. Tiskaya M, Al-Eesa NA, Wong FSL, Hill RG. Characterization of the bioactivity of two commercial composites. Dent Mater. 2019;35(12):1757-68. https://doi.org/10.1016/j. dental.2019.10.004

PMid:31699444 